\title{
Remote Psychological Interventions for Fear of Cancer Recurrence: Scoping Review
}

Clizia Cincidda $^{1,2}$, MSc; Silvia Francesca Maria Pizzoli ${ }^{1}, \mathrm{PhD}$; Gabriella Pravettoni ${ }^{1,2}, \mathrm{PhD}$

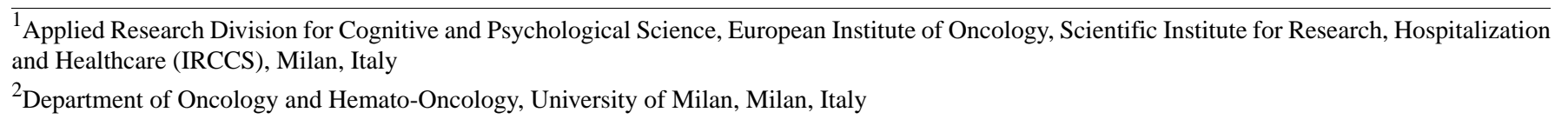

\section{Corresponding Author:}

Clizia Cincidda, MSc

Applied Research Division for Cognitive and Psychological Science

European Institute of Oncology

Scientific Institute for Research, Hospitalization and Healthcare (IRCCS)

via Ripamonti, 435

Milan, 20132

Italy

Phone: 390257489207

Email: clizia.cincidda@ieo.it

\section{Abstract}

Background: Patients with cancer and survivors may experience the fear of cancer recurrence (FCR), a preoccupation with the progression or recurrence of cancer. During the spread of COVID-19 in 2019, patients and survivors experienced increased levels of FCR. Hence, there is a greater need to identify effective evidence-based treatments to help people cope with FCR. Remotely delivered interventions might provide a valuable means to address FCR in patients with cancer.

Objective: The aim of this study is to first discuss the available psychological interventions for FCR based on traditional cognitive behavioral therapies (CBTs) or contemporary CBTs, in particular, mindfulness and acceptance and commitment therapy, and then propose a possible approach based on the retrieved literature.

Methods: We searched key electronic databases to identify studies that evaluated the effect of psychological interventions such as CBT on FCR among patients with cancer and survivors.

Results: Current evidence suggests that face-to-face psychological interventions for FCR are feasible, acceptable, and efficacious for managing FCR. However, there are no specific data on the interventions that are most effective when delivered remotely.

Conclusions: CBT interventions can be efficacious in managing FCR, especially at posttreatment, regardless of whether it is delivered face to face, on the web, or using a blended approach. To date, no study has simultaneously compared the effectiveness of face-to-face, web-based, and blended interventions. On the basis of the retrieved evidence, we propose the hypothetical program of an intervention for FCR based on both traditional CBT and contemporary CBT, named Change Of Recurrence, which aims to improve the management of FCR in patients with cancer and survivors.

(JMIR Cancer 2022;8(1):e29745) doi: $\underline{10.2196 / 29745}$

\section{KEYWORDS}

fear of cancer recurrence; cognitive behavioral therapy; acceptance and commitment therapy; mindfulness; eHealth; blended intervention

\section{Introduction}

\section{Fear of Cancer Recurrence}

Along the trajectory of cancer care, which in recent years has been extended because of new technologies [1], patients and survivors might experience fear of cancer recurrence (FCR), which is the concern that cancer will progress when it is stable or that it may return after the end of treatment [2]. Low levels of FCR could be adaptive for patients and survivors, as they promote and encourage the maintenance of medical follow-up, engagement in healthy lifestyle changes, and greater attention to signs of new or recurring cancer [3]. However, when FCR becomes distressing, patients can engage in negative health behaviors (eg, overusing health services and avoiding 
appropriate tests to identify cancer recurrence) and experience higher psychological distress and poorer quality of life (QoL) [3-5]. In addition, significant relationships emerged between FCR and certain sociodemographic variables (eg, younger age and having young children) and psychological factors (eg, anxiety and depression), whereas conflicting data emerged regarding the characteristics of tumor and cancer treatments [3]. With the advent of emerging nanomaterial-based approaches that would promote early diagnosis [6], these could favor better treatment efficacy and a reduction in FCR. However, this is an innovative area that is yet to be explored.

Currently, patients with cancer and survivors experience higher levels of loneliness, FCR, anxiety, and depression because of the diffusion of COVID - 19. Indeed, the pandemic forced people to social distance and caused several challenges for patients with cancer and survivors, such as maintaining social support and continuing their cancer treatment or medical check-ups regularly [7-10]. Despite the current situation, the need to identify effective evidence-based treatments to help people cope with FCR has increased in the past decade. In clinical settings, clinicians can help patients and survivors using psychological support, psychoeducational interventions, or psychotherapy. Data from recent systematic reviews and a meta-analysis of 23 controlled trials have shown that psychological interventions for FCR are feasible, acceptable, and efficacious for managing FCR, having a small-to-medium but a robust effect that persists at postintervention (Hall et al [11]: Hedge $g=-0.36$; Tauber et al [5]: Hedge $g=0.33$ ) and follow-up (Tauber et al [5]: Hedge $g=0.30$ ) [4,12]. Interestingly, in these reviews, most psychological interventions were based on traditional cognitive behavioral therapies (CBTs) or contemporary CBTs (eg, mindfulness and acceptance and commitment therapies [ACTs]). The first, traditional CBTs, focused on the contents of thoughts and aimed to identify and modify people's negative thoughts or biases to reduce dysfunctional emotions and promote psychological adjustment, whereas the second, contemporary CBTs, focused on mental processes and aimed to modify how people relate to their inner experiences [3-5,11,12]. In particular, Tauber et al [5] found that FCR symptoms were more responsive to contemporary CBTs (Hedge $g=0.42$ ) compared with traditional CBT (Hedge $g=0.24$ ) at postintervention; however, this greater effect did not persist over time [5]. Considering the existence of several declinations of CBT approaches, it is important to understand the interventions that are effective in helping patients with cancer with decreasing FCR. As the pandemic forced patients with cancer into obliged isolation, a critical analysis of the different modalities in which these types of therapies can be delivered (eg, face to face or via remote and web-based approaches) might be useful. Indeed, apart from traditional in-presence interventions, blended (a mixed method comprising both web-based and face-to-face therapy) or remote care for patients with cancer has been increasingly applied [13]. Furthermore, during the pandemic, the management of patients with cancer has raised medical issues $[14,15]$ and psychological issues [16].

\section{Objective}

In this paper, we aim to critically revise and systematize the available evidence on the effectiveness of different modalities and approaches of CBT psychological interventions for FCR. Specifically, this review aims to summarize studies dealing with face-to-face, remote, and blended interventions based on traditional CBTs or contemporary CBTs, in particular, mindfulness and ACT, used to reduce FCR. Finally, we propose a possible program based on the retrieved literature.

\section{Methods}

Electronic searches were performed using PubMed, MEDLINE, and Embase between November and December 2020, with no time limits. Original articles were considered in English, Italian, or Spanish languages, with participants aged $\geq 18$ years. Keywords searched in titles and abstracts included fear of cancer recurrence combined with terms such as cognitive behavioral therapy, acceptance and commitment therapy, mindfulness, mindfulness-based stress reduction, blended therapy, face-to-face intervention, and online intervention. The reference lists in the relevant systematic reviews were manually searched for additional contributions that met our inclusion criteria. The search was limited to only full-text articles. The studies included in this paper met the following main criteria: (1) articles dealing with patients with cancer with FCR, (2) articles including traditional or contemporary cognitive psychological interventions for FCR (CBT, ACT, and mindfulness), and (3) articles presenting quantitative data or study protocols. Commentaries, editorials, and conference proceedings were excluded. Research papers on traditional and contemporary CBT interventions (classical CBT, mindfulness, and ACT) were included.

Initially, the search strategy yielded 470 articles that were screened for irrelevant or duplicate articles. The remaining articles were assessed and selected by screening the abstracts, followed by full-text reading and selection according to the predefined inclusion and exclusion criteria. Of the 470 articles, $35(7.4 \%)$ articles that focused on psychological interventions for reducing FCR were selected. The results were organized according to the modality of delivery of the therapy (face to face, remote, and blended).

\section{Results}

\section{Face-to-face Traditional CBT, Mindfulness, and ACT}

Psychological interventions for patients with cancer and survivors based on the principles of traditional CBT aim to encourage patients to identify, express, and deal with their fears and emotional reactions related to cancer and improve their ability to cope with them to maintain their QoL and evaluate and alter life priorities [17-23]. Traditional CBT interventions can be delivered in groups $[17,19,21,22,24]$ or individually $[18,20,23,25]$ and have short-term benefits [17,19,22-24] and significant long-term effects on FCR [17,18,20].

Clinicians often begin the interventions with psychoeducation on FCR to explain what it is and how it presents and maintains during everyday life [22,23]. Moreover, through these 
interventions, patients can improve their problem-solving skills and use of personal and social resources, enhance their self-esteem and autonomy [20,21], and look into their illness beliefs and behaviors [18]. Specifically, patients address irrational thoughts through cognitive reframing to reduce catastrophic interpretations of physical symptoms and emotions [19,21-23]. Some examples of psychological interventions are Side by Side, a couple of skill interventions proposed by Heinrichs et al [24], and the adjustment to the fear, threat or expectation of recurrence intervention theorized by Humphris and Rogers [18]. In particular, the Side by Side program takes place at the couple's home and comprises 4 biweekly face-to-face sessions with a therapist, focused on communication skills and dyadic coping [24]. Instead, the adjustment to the fear, threat or expectation of recurrence intervention is for patients-the caregiver can only be included if desired by the patient - and is intended to encourage patients to express and process fears related to FCR and explore illness beliefs and behaviors. During the sessions, patients also practiced relaxation exercises [18].

Psychological interventions based on mindfulness, which is a particular way to pay attention to the present moment without judgment, ensure that people turn away from unhealthy beliefs, thoughts, or emotions, maintaining awareness of the present moment [26]. Clinicians can choose between different mindfulness-based programs, such as mindfulness-based stress reduction (MBSR), mindful movement program, or mindfulness-based cognitive therapy (MBCT) [4,5,27]. The MBSR program aims to self-regulate arousal in response to stressful situations or symptoms and reduce the intensity of cognitive processes by lowering the frequency of negative automatic thinking [4,27]. This program comprises 1-hour session conducted by a psychologist and home practice following a manual and audiotapes (eg, sitting meditation, walking meditation, body scan, and yoga), with data showing that it has a significant effect on FCR in people with cancer at postintervention [28-32]. Instead, the mindful movement program combines mindfulness with self-directed movement for patients to explore and understand their thoughts, feelings, and sensations. Data report a significant effect on FCR at 12 weeks after treatment; however, this effect does not maintain at 18 weeks after treatment [33]. The MBCT program aims to teach participants to be more mindful in daily life through meditation exercises, yoga, group discussions, and didactic teaching. This program comprises 8 weekly sessions, a silent day, and daily homework. Compared with usual care, patients who receive this program report significantly lower levels of FCR (Cohen $d=0.27$ ) [27].

Finally, ACT interventions explain psychological distress through psychological inflexibility, a construct that comprises behaving under the strict control of rigid personal thoughts, feelings, and other internal experiences [34]. ACT aims to reduce psychological inflexibility, limit the use of maladaptive coping strategies, and enhance psychological flexibility, which lets people live mindfully according to their values and accept both negative and positive events [34]. However, in the literature, there were only $9 \%(3 / 35)$ of studies that applied ACT to FCR [35-37], and only 3\% (1/35) was a randomized controlled trial (RCT) assessing the feasibility and preliminary efficacy of ACT interventions for FCR at postintervention and over time [36]. Johns et al [36] proposed a group intervention based on ACT principles, which aimed to promote adaptive coping through acceptance, cognitive defusion, awareness, and perspective-taking exercises while supporting survivors of breast cancer (BC) in aligning their behavior with personal values to cope with fears. Furthermore, participants improved the skills learned during the session by performing home awareness practice [36]. Arch and Mitchell [35] developed a group manual and workbook for participants comprising experiential exercises, metaphors, discussions, and homework. This was aimed at helping participants to be aware of and accept thoughts and emotions about cancer, eliminate rigid thoughts and beliefs about cancer and themselves through psychological flexibility, and define personal values and commit to pursuing meaningful activities in line with those values [35]. All these interventions suggest that ACT intervention could be useful for reducing FCR [35-37]. Moreover, in the literature, a manualized intervention, called ConquerFear, focuses on reducing the impact of FCR based on metacognitive therapy, the Common Sense Model of illness, the Self-Regulation of Executive Function Model, and relational frame theory, which form the theoretical basis for ACT (more details are provided in Butow et al [38]). In particular, this intervention comprises 5 face-to-face sessions, each of which is associated with home exercises on the skills learned in the session. Patients, through the ConquerFear intervention, learned new strategies to control worry, modified dysfunctional beliefs related to worry, acquired appropriate monitoring and screening behaviors, learned to accept the uncertainty caused by a cancer diagnosis, and defined values and goals based on them. This intervention reduced FCR severity at posttreatment and over time [39,40]. A summary of the described face-to-face psychological interventions for FCR is provided in Table 1 . 
Table 1. Face-to-face psychological interventions.

\begin{tabular}{|c|c|c|c|c|}
\hline Therapy and authors & Cancer & Study design & Intervention and groups & Results \\
\hline \multicolumn{5}{|l|}{ Traditional CBT $^{\text {a }}$} \\
\hline Heinrichs et al [24] & $\mathrm{BC}^{\mathrm{b}}$ or $\mathrm{GC}^{\mathrm{c}}$ & $\mathrm{RCT}^{\mathrm{d}}$ & $\begin{array}{l}\text { - } \quad \text { Side by Side: } 4 \text { biweekly couple } \\
\text { skills sessions } \\
\text { - } \quad \text { Couples Control Program }\end{array}$ & $\begin{array}{l}\text { Side by Side had a greater effect on FoP } \\
\text { than the Couples Control Program; } \\
\text { however, this difference disappeared by } \\
16 \text { months after the diagnosis. }\end{array}$ \\
\hline $\begin{array}{l}\text { Herschebach et al } \\
{[17]}\end{array}$ & Different type & Longitudinal study & $\begin{array}{l}\text { - } 4 \text { session cognitive behavioral } \\
\text { group therapy } \\
\text { - Supportive experimental group } \\
\text { therapy } \\
\text { - } \quad \mathrm{UC}^{\mathrm{f}}\end{array}$ & $\begin{array}{l}\text { FoP decreased significantly over time in } \\
\text { both intervention groups in contrast to } \\
\text { the control group that showed only short- } \\
\text { term improvements. }\end{array}$ \\
\hline $\begin{array}{l}\text { Humphris and } \\
\text { Rogers [18] }\end{array}$ & Different type & RCT & $\begin{array}{l}\text { - } \text { AFTER }^{\mathrm{g}}: 6 \text { weekly sessions of } \\
\text { traditional CBT individual therapy } \\
\text { - } \mathrm{UC}\end{array}$ & $\begin{array}{l}\text { AFTER intervention improves } \mathrm{FCR}^{\mathrm{h}} \\
\text { only at the immediate short-term follow- } \\
\text { up (MWU': } \mathrm{z}=2.06 ; P=.04) \text {. }\end{array}$ \\
\hline Lebel et al [19] & $\begin{array}{l}\text { Survivors of BC } \\
\text { or ovarian cancer }\end{array}$ & $\begin{array}{l}\text { A single-arm multi- } \\
\text { site study }\end{array}$ & $\begin{array}{l}\text { - 6-week cognitive-existential } \\
\text { group intervention }\end{array}$ & $\begin{array}{l}\text { Significant reductions of FCR levels } \\
\text { immediately after it and at the 3-month } \\
\text { follow-up }\end{array}$ \\
\hline Manne et al [20] & GC & $\mathrm{RCT}$ & $\begin{array}{l}\text { - } \quad \mathrm{CCI}^{\mathrm{j}}: 7 \text { weekly sessions of individ- } \\
\text { ual therapy and } 1 \text { telephone ses- } \\
\text { sion } 2 \text { or } 3 \text { weeks after session } 7 \\
\text { A supportive counseling interven- } \\
\text { tion: } 7 \text { weekly sessions of individ- } \\
\text { ual therapy and } 1 \text { telephone ses- } \\
\text { sion } 2 \text { or } 3 \text { weeks after session } 7 \\
\text { UC }\end{array}$ & CCI did not affect FCR. \\
\hline Savard et al [22] & Different type & $\begin{array}{l}\text { Development and } \\
\text { feasibility }\end{array}$ & - 4 weekly group CBT sessions & Significant reductions of FCR levels \\
\hline Tomei et al [23] & Different type & RCT pilot & $\begin{array}{l}\text { - FCR intervention: 6-week ses- } \\
\text { sions }\end{array}$ & $\begin{array}{l}\text { Significant reduction of FCR levels at } \\
\text { postintervention and at 3-month follow- } \\
\text { up }\end{array}$ \\
\hline \multicolumn{5}{|l|}{ Contemporary CBT } \\
\hline $\begin{array}{l}\text { Crane-Okada et al } \\
{[33]}\end{array}$ & Survivors of BC & RCT pilot & $\begin{array}{l}\text { - } 12 \text {-week mindful movement pro- } \\
\text { gram intervention }\end{array}$ & $\begin{array}{l}\text { Significant effect on FCR at } 12 \text { weeks } \\
\text { posttreatment; however, this effect does } \\
\text { not maintain at } 18 \text { weeks after treatment }\end{array}$ \\
\hline $\begin{array}{l}\text { Lengacher et al } \\
\text { [28] }\end{array}$ & Survivors of BC & RCT & $\begin{array}{ll}\text { - } & 6 \text { - week } \mathrm{MBSR}^{\mathrm{k}} \text { program } \\
\text { - } & \mathrm{UC}\end{array}$ & $\begin{array}{l}\text { MBSR reduces FCR more than usual } \\
\text { care (11.6 vs } 9.3) \text { at } 6 \text { weeks. }\end{array}$ \\
\hline $\begin{array}{l}\text { Lengacher et al } \\
{[29]}\end{array}$ & Survivors of BC & $\begin{array}{l}\text { Feasibility of the in- } \\
\text { tervention }\end{array}$ & - $\quad$ 8-week MBSR program & Significant effect on FCR \\
\hline $\begin{array}{l}\text { Lengacher et al } \\
{[30]}\end{array}$ & $\mathrm{BC}$ & $\begin{array}{l}\text { A single-arm multi- } \\
\text { site study }\end{array}$ & $\begin{array}{ll}\text { - } & \text { 6-week MBSR (BC) program } \\
\text { - } & \mathrm{UC}\end{array}$ & $\begin{array}{l}\text { MBSR (BC) reduces FCR; MBSR (BC) } \\
\text { compared with UC had a favorable } \\
\text { change in FCR problems that mediated } \\
\text { the effect of MBSR (BC) on 6-week } \\
\text { change in perceived stress }(\mathrm{z}=2.12 ; \\
P=.03) \text { and state anxiety }(\mathrm{z}=2.03 ; P=.04)\end{array}$ \\
\hline $\begin{array}{l}\text { Lengacher et al } \\
{[31]}\end{array}$ & Survivors of BC & RCT & $\begin{array}{l}\text { - 2-hour sessions once per week for } \\
6 \text { weeks of an MBSR (BC) } \\
\text { - } \quad \text { UC }\end{array}$ & $\begin{array}{l}\text { Significant improvement of FCR in the } \\
\text { MBSR (BC) group compared with usual } \\
\text { care }\end{array}$ \\
\hline Victorson et al [32] & $\mathrm{PC}^{1}$ & RCT pilot & $\begin{array}{l}\text { - } 8 \text { - week MBSR intervention } \\
\text { - An attention control arm }\end{array}$ & $\begin{array}{l}\text { MBSR significantly reduces PC anxiety } \\
\text { and uncertainty intolerance }\end{array}$ \\
\hline
\end{tabular}




\begin{tabular}{|c|c|c|c|c|}
\hline Therapy and authors & Cancer & Study design & Intervention and groups & Results \\
\hline $\begin{array}{l}\text { Arch and Mitchell } \\
{[35]}\end{array}$ & Survivors of BC & Pilot study & $\begin{array}{l}\text { - } 7 \text { weekly 2-hour sessions of } \\
\mathrm{ACT}^{\mathrm{m}}\end{array}$ & $\begin{array}{l}\text { FCR decreases through } 1 \text { week following } \\
\text { the last group session (post; Cohen } \\
d=0.34 ; P<.05 \text { ) and } 3 \text { months following } \\
\text { post (Cohen } d=0.66 ; P=.001 \text { ) but not } \\
\text { during the month-long baseline period } \\
\text { (Cohen } d=0.11 ; P=.43 \text { ) }\end{array}$ \\
\hline Johns et al [36] & Survivors of BC & $\mathrm{RCT}$ & $\begin{array}{l}\text { - } 6 \text { weekly } 2 \text { - hour group sessions } \\
\text { of ACT } \\
6 \text { weekly } 2 \text { - hour group sessions } \\
\text { of } \mathrm{SE}^{\mathrm{n}} \\
\text { - } \quad \text { One } 30 \text { - minute group coaching } \\
\text { session }\left(\mathrm{EUC}^{\mathrm{O}}\right)\end{array}$ & $\begin{array}{l}\text { SE and ACT reduce FCR severity over } \\
\text { time; however, only ACT produced sig- } \\
\text { nificant reductions at each time point } \\
\text { relative to baseline, with between-group } \\
\text { differences at time point } 4 \text { substantially } \\
\text { favoring ACT over SE (Cohen } d=0.80 \text {; } \\
P<.001 \text { ) and EUC (Cohen } d=0.61 \text {; } \\
P<.01)\end{array}$ \\
\hline $\begin{array}{l}\text { Marín and Soriano } \\
\text { [37] }\end{array}$ & $\mathrm{BC}$ & Open trial & $\begin{array}{l}\text { - } 1 \text { session of ACT } \\
\text { - Waiting list }\end{array}$ & $\begin{array}{l}\text { Defusion contributes to decreasing FCR, } \\
\text { and this effect is maintained } 3 \text { months } \\
\text { after the intervention. }\end{array}$ \\
\hline Butow et al $[38,39]$ & $\begin{array}{l}\mathrm{BC} \text { or } \mathrm{CRC}^{\mathrm{p}} ; \mathrm{BC} \\
\text { or } \mathrm{CRC} \text { or } \\
\text { melanoma }\end{array}$ & $\begin{array}{l}\text { Study protocol of an } \\
\text { RCT; RCT }\end{array}$ & $\begin{array}{l}\text { - ConquerFear intervention: } 5 \text { face- } \\
\text { to-face sessions over } 10 \text { weeks } \\
\text { Taking-it-Easy relaxation therapy: } \\
5 \text { face-to-face sessions over } 10 \\
\text { weeks }\end{array}$ & $\begin{array}{l}\text { ConquerFear is efficacy compared with } \\
\text { attention control in reduction of FCR } \\
\text { immediately after therapy and } 3 \text { and } 6 \\
\text { months later }\end{array}$ \\
\hline Smith et al [40] & $\mathrm{BC}$ & Pilot study & $\begin{array}{l}\text { - ConquerFear intervention: } 5 \text { face- } \\
\text { to-face sessions over } 10 \text { weeks }\end{array}$ & $\begin{array}{l}\text { ConquerFear is feasible, acceptable, and } \\
\text { shows potential efficacy for FCR }\end{array}$ \\
\hline
\end{tabular}

${ }^{\mathrm{a} C B T}$ : cognitive behavioral therapy.

${ }^{\mathrm{b}} \mathrm{BC}$ : breast cancer.

${ }^{\mathrm{c}} \mathrm{GC}$ : gynecologic cancer.

${ }^{\mathrm{d}} \mathrm{RCT}$ : randomized controlled trial.

$\mathrm{e}_{\mathrm{FoP}}$ : Fear of Progression.

${ }^{\mathrm{f}} \mathrm{UC}$ : usual care.

g AFTER: adjustment to the fear, threat or expectation of recurrence.

${ }^{\mathrm{h}} \mathrm{FCR}$ : fear of cancer recurrence.

${ }^{\mathrm{i}}$ MWU: Mann-Whitney $U$ test.

${ }^{\mathrm{j}} \mathrm{CCI}$ : coping and communication-enhancing intervention.

${ }^{\mathrm{k}}$ MBSR: mindfulness - based stress reduction.

${ }^{1} \mathrm{PC}$ : prostate cancer.

${ }^{\mathrm{m}} \mathrm{ACT}$ : acceptance and commitment therapy.

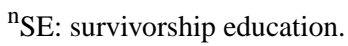

${ }^{\circ}$ EUC: Enhanced Usual Care.

${ }^{\mathrm{P}} \mathrm{CRC}$ : colorectal cancer.

All these approaches, which are delivered face-to-face, present some criticisms: they were relatively expensive and time and resource intensive, and patients could be reluctant to return to the hospital where cancer treatment took place [41]. In the current period, such limits might be overcome by remotely delivered internet-based interventions.

\section{Traditional CBT, Mindfulness, and ACT Delivered Through eHealth}

Over the past decades, owing to the increasing use of new technologies for the treatment of psychological aspects, clinicians have applied remotely delivered psychological techniques in the field of mental health and health care settings, giving rise to eHealth [42]. Web-based interventions overcame the criticisms of face-to-face interventions, as they can be performed from patients' homes, even for those who are in remotely located places or have reduced mobility for health issues $[43,44]$. Moreover, eHealth reduces health care costs, as it requires few economical resources to be allocated for personnel needed compared with the need for personnel's engagement in face-to-face therapies [45]. Finally, eHealth also offers the chance for self-management and continuity of care [46]. However, there are some disadvantages related to eHealth interventions, such as the lack or reduction of personal interaction, poor adherence, and less engagement [47].

Considering the clinical target, eHealth proved to be effective in the field of mental health and psychological treatments $[42,48]$, whereas in specific oncological settings, it has limited and inconsistent findings $[49,50]$. 
eHealth based on CBT involves the delivery of clinical CBT content via the internet and provides content in several formats, for example, text, video, and audio files and interactive elements.

Regarding traditional CBT, Lichtenthal and al [51] proposed a home-delivered cognitive bias modification intervention to reduce FCR. The intervention, Attention and Interpretation Modification for Fear of Breast Cancer Recurrence (AIM-FBCR), targets 2 types of cognitive biases: attentional bias, which is assessed through a modified dot-probe task, and interpretation bias, which is assessed through a word-sentence association paradigm [51]. In a preliminary pilot randomized controlled study $(\mathrm{n}=110)$, participants completed 8 personalized treatment sessions twice a week for 4 weeks, and the results showed that this intervention was effective in reducing health worries in patients with cancer [51]. Another example is the web-based self-help training performed by van Helmondt et al [52]. The program, Cancer Recurrence Self - Help Training trial, comprises a psychoeducation model and a model based on the basic principles of CBT, and 4 optional modules (rumination, action, relaxation, and reassurance) to choose from. Each module comprises an instructive part (texts, videos, or audio files) and a part made of exercises. Patients could be supported on the web personally by emailing a coach [52]. However, the same authors found that there was no effect of this intervention on FCR [44].

Regarding contemporary CBT, specifically for the concerns regarding eHealth mindfulness-based programs used alone in the cancer settings, evidence related to FCR is scarce. However, the internet-based MBCT (eMBCT) intervention, which is a combination of MBCT and $\mathrm{CBT}$, demonstrated reductions in FCR (Cohen $d=0.53$ ) and rumination and improvements in mental health-related QoL compared with standard care [27]. Patients accessed this intervention, which was delivered individually, through a secure website in which they found an introduction module and daily meditation exercises with meditation audio files. During the intervention, the patients had to fill out practice diaries. The intervention lasted 8 weeks and included a silent day, at the end of which patients were asked to write about their experiences in an essay and send it to the therapist, who returned written feedback [27]. On the basis of MBSR, there is a mobile MBSR for BC program proposed by Lengacher et al [53]. Patients accessed this program via an iPad after having received a user manual and orientation on how to use the iPad. The content of the program comprised video files on formal meditative techniques (eg, sitting meditation, walking meditation, body scan, and gentle Hatha yoga) and audio files on informal meditative techniques (eg, integrating mindfulness into daily life activities). Moreover, participants could learn the formal and informal meditative techniques provided on the iPad through a physical manual. The results of a pilot study on this program showed that it might be feasible and acceptable, improving FCR scores [53].

Finally, with regard to web-based interventions based on ACT, the studies recovered in the literature were few, and in the oncology field, we found only $11 \%$ (4/35) of studies; $50 \%$ (2/4) of them were for patients with cancer and the others for partners [54-57]. One of the studies explored the acceptability, feasibility, efficacy, and cost-effectiveness of an internet intervention for survivors of BC called iNNOVBC [57]. To date, the authors have presented only the protocol of this intervention, which comprises 10 modules, 5 of which are optional. In the mandatory modules, there was 1 about anxiety, worries, and fear of recurrence; for that reason, we presented this program. The key components were psychoeducation; 4 of the 6 core processes of psychological flexibility (acceptance, cognitive defusion, values, and committed action); behavioral activation; and relaxation that patients learned through experiential exercises, metaphors, and homework. During therapy, patients could communicate with a therapist via SMS text messaging, chat, email, and videoconference [57].

Finally, in the literature, we found examples of web-based interventions based on multiple theories, such as e-TC and iConquerFear $[49,58]$. The e-TC includes 6 interactive modules that take approximately an hour to complete. The therapeutic contents were based on traditional CBT, ACT, metacognitive therapy, mindfulness, and relaxation. Patients were trained to restructure or accept their unpleasant thoughts and feelings and cope with stressful situations [49]. The results of the pilot tests showed that the participants were highly satisfied with the program, although they suggested that limited time for men was an obstacle to using and completing the program, and men with a more recent diagnosis and a level of higher distress may be more likely to commit to the program. However, e-TC appears to be a feasible and acceptable web-based intervention for survivors of testicular cancer [49]. To date, no data have supported the effectiveness of this intervention. Moreover, the iConquerFear intervention, based on the aforementioned ConquerFear therapy manual [38], comprises 6 modules, 5 therapeutic and 1 as the introduction, including audio, video, and text contents. Patients completed the modules in 1 to 2 hours over 1 to 2 weeks, and between the modules, they practiced with the skills learned [58]. However, no data supported the effectiveness of this intervention, although there is only a qualitative evaluation of the usability of iConquerFear [58].

A summary of the aforementioned studies on psychological interventions delivered through eHealth is provided in Table 2. 
Table 2. Remote psychological interventions.

\begin{tabular}{|c|c|c|c|c|}
\hline Therapy and authors & Cancer & Study design & Intervention & Results \\
\hline \multicolumn{5}{|l|}{ Traditional CBT ${ }^{\mathrm{a}}$} \\
\hline $\begin{array}{l}\text { Lichtenthal et al } \\
\text { [51] }\end{array}$ & $\mathrm{BC}^{\mathrm{b}}$ & $\mathrm{RCT}^{\mathrm{c}}$ pilot & $\begin{array}{l}\text { - } A I M-\mathrm{FBCR}^{\mathrm{d}}: 8 \text { personalized treatment sessions } \\
\text { of } 30 \text { minutes each administered twice a week } \\
\text { for } 4 \text { weeks } \\
\text { - } \quad \text { A control condition program }\end{array}$ & $\begin{array}{l}\text { The results of the current pilot } \\
\text { study suggest the promise of } \\
\text { AIM - FBCR in reducing FCR }{ }^{\mathrm{e}} \text { in } \\
\text { survivors of BC }\end{array}$ \\
\hline $\begin{array}{l}\text { van Helmondt et } \\
\text { al }[44,52]\end{array}$ & $\begin{array}{l}\text { Survivors of } \\
\text { BC }\end{array}$ & $\begin{array}{l}\text { Study protocol; } \\
\text { RCT }\end{array}$ & $\begin{array}{l}\text { - The Cancer Recurrence Self - help Training trial: } \\
\text { less fear after cancer-a tailored web-based self- } \\
\text { help training ( } 2 \text { basic modules and } 4 \text { optional } \\
\text { modules) } \\
\text { - UC }\end{array}$ & $\begin{array}{l}\text { There was no effect of the CBT - } \\
\text { based web-based self - help train- } \\
\text { ing Less fear after cancer on FCR } \\
\text { in the study }\end{array}$ \\
\hline
\end{tabular}

\section{Contemporary CBT}

Compen et al Different type RCT

[27]

of cancer

Lengacher et al $\quad \mathrm{BC} \quad$ Feasibility

[53]

Mendes-Santos et Survivors of

al [57] BC

Study protocol $\mathrm{BC}$

Heiniger et al $\quad \mathrm{TC}^{\mathrm{k}} \quad$ Pilot study [49]

Smith et al [58] Different type Study protocol of cancer
- Individual internet-based $\mathrm{MBCT}^{\mathrm{g}}$ : access to a secure website containing material for 8 weeks plus a silent day and an inbox+weekly asynchronous written interaction with a therapist over email

- $\quad$ MBCT: 8 weekly 2.5-hour group sessions, a 6hour silent day, and daily home practice assignments guided by audio files

- $\mathrm{UC}$

- $\quad \operatorname{mMBSR}(\mathrm{BC})^{\mathrm{h}}$ : sitting and walking meditation, body scan, and yoga and is designed to deliver weekly 2 - hour sessions for 6 weeks using an iPad

- $\quad$ iNNOVBC $^{\mathrm{i}}$ : a 10-week guided internet-delivered individually tailored $\mathrm{ACT}^{\mathrm{j}}$ influenced $\mathrm{CBT}$ intervention

- UC

- e-TC: 6 interactive modules for 10 weeks

- $\quad$ iConquerFear: 5 therapeutic modules completed in 1 to 2 hours over 1 to 2 weeks
Compared with UC, both interventions reduced FCR
There was a significant improvement from baseline to 6 weeks after mMBSR (BC) in FCR

Not yet available

e-TC appeared to be a feasible and acceptable web-based intervention for survivors of TC

${ }^{\mathrm{a} C B T}$ : cognitive behavioral therapy.

${ }^{\mathrm{b}} \mathrm{BC}$ : breast cancer.

${ }^{\mathrm{c}} \mathrm{RCT}$ : randomized controlled trial.

${ }^{\mathrm{d}}$ AIM - FBCR: Attention and Interpretation Modification for Fear of Breast Cancer Recurrence.

${ }^{\mathrm{e}} \mathrm{FCR}$ : fear of cancer recurrence.

${ }^{\mathrm{f}} \mathrm{UC}$ : usual care.

${ }^{\mathrm{g}}$ MBCT: mindfulness-based cognitive therapy.

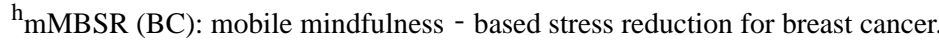

${ }_{i}$ iNNOVBC: a guided internet-delivered individually tailored acceptance and commitment therapy-influenced cognitive behavioral intervention to improve psychosocial outcomes in breast cancer survivors.

${ }^{\mathrm{j}} \mathrm{ACT}$ : acceptance and commitment therapy.

${ }^{\mathrm{k}} \mathrm{TC}$ : testicular cancer.

\section{Traditional CBT, Mindfulness, and ACT Through Blended Care}

Currently, in the field of eHealth treatments, the use of blended care is gaining rising visibility. Blended treatment or blended care are defined in literature as "technology-supported care," with the term blended describing a combination of web-based and offline elements inside the same care-flow intervention. Generally, the offline part corresponds to face-to-face sessions, whereas for the web-based element, patients accessed a website or workbook, which facilitated further skill acquisition and learning [41]. To date, a single definition of what blended 
intervention exactly reserves was absent, as blended care is currently built with different approaches across studies [48].

In blended treatments, web-based and offline components are not standalone treatment pathways but rather interrelated methods that are strategically combined to build an intervention that merges the potential benefits of the 2 approaches [48,59]. In particular, blended care shares with eHealth the advantage of being flexible in application, having good accessibility, and saving travel time and costs $[59,60]$. It shares with face-to-face interventions the benefit of having a therapist as a guide, which increases adherence, prevents dropout, facilitates increased treatment intensity, and leads to better results than unguided treatments [61]. To date, the literature has demonstrated that blended therapy displays encouraging effects $[48,62]$ and has shown efficacy in reducing FCR among early-stage survivors of cancer [63]. CBT was the first approach that was used to build blended interventions in the field of psychological health [64], emerging as an evolution of the classical CBT method and the method that was internet-delivered. Indeed, blended care CBT treatments (BC-CBTs) blend classical therapist-led CBT sessions with internet-delivered CBT components, and it constitutes an integrated therapy, putting together the gains of both approaches while relieving the limits of the single approaches. The interactive presence of the therapist, for instance, allows for the creation of a therapeutic alliance, which in turn is associated with higher motivation to begin and maintain commitment in care $[65,66]$. Furthermore, the presence of a therapist allows for a fair degree of personalization of treatment plans. Specifically, the therapist using BC-CBT can decide the extent to which face-to-face sessions, live video-based sessions with interactions between therapist and client, and remote digital care tools (lessons and exercises) that can be accessed by the client between sessions can be combined $[67,68]$. Moreover, internet CBT with the therapist's support leads to better clinical outcomes, more stable results in time, and higher adherence compared with unsupported ones (eHealth) $[69,70]$.

Considering traditional CBT, the Survivors' Worries of Recurrent Disease study is an example of a BC-CBT intervention that combines traditional CBT, which is delivered face-to-face, with web-based activities (or workbook activities) $[41,63,71]$. This intervention aims to modify the cognitions and behaviors that maintain a high FCR through cognitive reframing, exposure and response prevention, psychoeducation, mindfulness, and relaxation exercises. It includes 5 face-to-face therapy sessions and 3 web-based or telephone sessions with a trained therapist. Participants could access a supportive website or workbook along with the therapy. During the first session, participants conceptualized their personal FCR model, which guided the course of the therapy. Subsequent sessions focused on acceptance, cognitive restructuring, and behavior modification. The final sessions consolidated the progress made by the patient and established a relapse prevention plan. Participants did homework to improve the skills learned during therapy. In an RCT of 88 survivors of cancer with high levels of FCR, participants who received this intervention had significantly less FCR compared with those who were allocated to the standard care group. The effect size was moderate to large
(Cohen $d=0.76$ ), and both the clinical and self-reported improvements in FCR were higher in the BC-CBT group compared with the control group [63]. Finally, a recent study showed that the Survivors' Worries of Recurrent Disease intervention was effective in reducing FCR compared with treatment as usual in the long term (mean difference -1.787 , $95 \% \mathrm{CI}-3.251$ to $-0.323 ; P=.02$ at 15 months follow-up) [47].

Another example is the blended care for FCR study proposed by Luigjes-Huizer et al [72]. This intervention was developed to be delivered by primary care and not by professionals and institutes specializing in psycho-oncology, as the role of primary care in cancer and survival care is increasing. In particular, general practitioners and mental health workers provided an intervention specifically designed for FCR based on CBT, clinical experience, and input from patients, with web-based modules that focused on normalization, psychoeducation, and self-management. There were 2 modules based on CBT and 5 optional modules (eg, rumination, avoidance, relaxing, reassuring, and undertaking activities). The authors are conducting a 2 -armed cluster-randomized trial to evaluate the effectiveness of this intervention [72].

In literature, there is another blended intervention based on traditional CBT, the colorectal cancer distress reduction intervention, which was proposed for survivors of colorectal cancer, which was not specific for FCR [73]. However, we propose this intervention as it comprises 3 separate modules, each of which deals with a specific ailment that the patient may experience, namely distress because of physical consequences, anxiety and FCR, and depression. It aims to facilitate adjustment and coping, reduce distress, and modify cognitions and behaviors. It lasted 14 weeks and comprised 5 individual sessions and 3 telephone consultations, combined with the use of the interactive self-management website, where patients found the homework. Patients discussed their homework completed on the website with a therapist during the individual sessions. In the first session, patients reported their cancer follow-up experiences with a focus on treatment goals, the distress they are experiencing, and their own unmet needs. During the second session, the therapist introduced and explained the basic skills of the CBT applied to the first module. The following sessions included psychoeducation, cognitive restructuring, behavior modification, and relaxation. In the last 2 sessions, the therapist and patient evaluated the reduction of distress and discussed the consolidation of long-term skills. The website included a general introduction module comprising 2 web-based homework sessions focused on introducing CBT and identifying personal goals. A total of 3 specific modules, including different types of self-management activities (eg, psychoeducational scripts, assignments tasks, screening tests, audio clips, and peer videos) and a general closing module focused on goal evaluation and relapse prevention. A 2-arm multicenter RCT of 160 survivors of colorectal cancer with high levels of ailment was initiated by the authors [73]. However, a cognitive behavior therapist decided to treat a 74-year-old male survivor of colorectal cancer with this intervention for 4 months and reported an improvement in psychological distress after intervention [74]. 
Regarding blended mindfulness or ACT-based interventions, there have been studies. On the basis of the aforementioned ConquerFear therapy, researchers want to test the efficacy in the short- and long-terms of a therapist-guided version of iConquerFear in reducing FCR and improving QoL in survivors of colorectal cancer. This intervention differs from iConquerFear because of the presence of the therapist through a messenger function with whom patients can communicate asynchronously. The therapist had the role of a motivator and coach, answering the questions and giving feedback on the exercises and written material [75]. A summary of the described studies is presented in Table 3.

Table 3. Blended psychological interventions.

\begin{tabular}{|c|c|c|c|c|}
\hline Therapy and authors & Cancer & Study design & Intervention & Results \\
\hline \multicolumn{5}{|l|}{ Traditional $\mathbf{C B T}^{\mathbf{a}}$} \\
\hline $\begin{array}{l}\text { van de Wal et al } \\
{[47,63,71]}\end{array}$ & $\begin{array}{l}\mathrm{BC}^{\mathrm{b}}, \mathrm{PC}^{\mathrm{c}} \text {, or colorectal; } \\
\text { survivors; } \mathrm{BC}, \mathrm{PC} \text {, and } \\
\mathrm{CRC}^{\mathrm{d}}\end{array}$ & $\begin{array}{l}\text { Study protocol; } \\
\text { RCT }^{\mathrm{e}} \text {; RCT }\end{array}$ & $\begin{array}{l}\text { The SWORD }{ }^{\mathrm{f}} \text { study: } 5 \text { individuals } \\
\text { 1-hour } \mathrm{F}^{\mathrm{g}} \mathrm{F}^{\mathrm{g}} \text { sessions+three } 15- \\
\text { minute web-based sessions based } \\
\text { on traditional CBT; } \mathrm{UC}^{\mathrm{h}}\end{array}$ & $\begin{array}{l}\text { - SWORD had a greater effect on } \\
\text { FCR }^{\mathrm{i}} \text { than UC with a moderate- } \\
\text { to-large effect size (Cohen } \\
\mathrm{d}=0.76 \text { ). } \\
\text { SWORD had a greater effect on } \\
\text { FCR than UC (mean difference } \\
-1.787,95 \% \mathrm{CI}-3.251 \text { to - } \\
0.323 ; P=.02 \text { ) at the } 15 \text {-month } \\
\text { follow-up. }\end{array}$ \\
\hline $\begin{array}{l}\text { van de Wal et al } \\
{[41]}\end{array}$ & Survivors of BC & Case study & $\begin{array}{l}\text { The SWORD study: } 7 \text { F2F therapy } \\
\text { sessions and } 1 \text { telephone session } \\
\text { based on traditional CBT }\end{array}$ & $\begin{array}{l}\text { - CBT reduced FCR over time (last } \\
\text { follow-up at } 12 \text { months after ther- } \\
\text { apy). }\end{array}$ \\
\hline $\begin{array}{l}\text { Luigjes-Huizer et } \\
\text { al [72] }\end{array}$ & j & Study protocol & $\begin{array}{l}\text { BLANKET }^{\mathrm{k}} \text { : } 2 \text { CBT modules+5 } \\
\text { optional modules; UC }\end{array}$ & - \\
\hline $\begin{array}{l}\text { Leermakers et al } \\
\text { [73] }\end{array}$ & Survivors of CRC & Study protocol & $\begin{array}{l}\text { CORRECT }^{1}: 5 \text { F2F sessions }+3 \\
\text { telephone sessions and an interac- } \\
\text { tive self-management website; UC }\end{array}$ & - \\
\hline Döking et al [74] & Survivors of CRC & Case study & $\begin{array}{l}\text { CORRECT for } 4 \text { months: } 5 \mathrm{~F} 2 \mathrm{~F}+3 \\
\text { telephone sessions and an interac- } \\
\text { tive self-management website }\end{array}$ & $\begin{array}{l}\text { - The intervention was successful } \\
\text { in reducing the distress of a sur- } \\
\text { vivor of cancer. }\end{array}$ \\
\hline
\end{tabular}

\section{Contemporary CBT}

Lyhne et al [75] Survivors of CRC Study protocol

${ }^{\mathrm{a}} \mathrm{CBT}$ : cognitive behavioral therapy.

${ }^{\mathrm{b}} \mathrm{BC}$ : breast cancer.

${ }^{\mathrm{c}} \mathrm{PC}$ : prostate cancer.

${ }^{\mathrm{d}} \mathrm{CRC}$ : colorectal cancer.

${ }^{\mathrm{e}} \mathrm{RCT}$ : randomized controlled trial.

'SWORD: Survivors' Worries of Recurrent Disease.

${ }^{\mathrm{g}} \mathrm{F} 2 \mathrm{~F}$ : face to face.

${ }^{\mathrm{h}} \mathrm{UC}$ : usual care.

${ }^{\mathrm{i}}$ FCR: fear of cancer recurrence.

${ }^{\mathrm{j}}$ The type of cancer was not specified.

${ }^{\mathrm{k}}$ BLANKET: blended care for fear of cancer recurrence.

${ }^{1}$ CORRECT: colorectal cancer distress reduction.

\section{Discussion}

\section{Principal Findings}

On the basis of the data presented in the literature, we could infer that a psychological intervention based on CBT is efficacious in managing FCR, especially at posttreatment $[4,5,11,12]$. Taking into consideration the results of traditional CBT, almost all psychological interventions reduced FCR at

postintervention and follow-up regardless of whether they were delivered face to face, on the web, or blended $[17,19,41,51,63,71]$. Only 1 study did not show any effect on FCR [44]. The remaining studies reduced the level of FCR only at posttreatment [18,20,22-24]. Moreover, there was a lack of data on the efficacy of 2 blended interventions based on traditional CBT [72,73]. To date, no study has simultaneously 
compared the effectiveness of face-to-face, web-based, and blended interventions.

Regarding psychological interventions based on mindfulness, only 1 RCT study compared MBCT and eMBCT with usual care and found that MBCT and $\mathrm{MBCT}$ were equally efficacious compared with treatment as usual in reducing FCR [27,76,77]. In general, face-to-face and web-based interventions reduced FCR at posttreatment [28-33,53]. However, there was a lack of studies on blended interventions based on mindfulness.

The retrieved studies in the literature on ACT reported only protocols and feasibility or qualitative studies, with no quantitative data on the effectiveness of such an approach, except for 2 RCTs -1 that provided a face-to-face intervention and the other 1 a web-based intervention [35-37,57]. However, little data on the feasibility of this approach have yielded promising results [56]. Even for ACT, no studies used blended interventions.

Finally, there were 2 programs based on multiple theories: ConquerFear, which clinicians could use face to face, via the web, or as blended; and e-TC. However, there was only quantitative data supporting the efficacy of face-to-face ConquerFear, which had a short and long-time effect on FCR $[39,40]$.

Hence, it was difficult to decide which one to choose. If for interventions based on traditional CBT, there were more data, for the contemporary CBT, the information would still be limited, even more so if we take into consideration the new methods of administering the interventions. Although it is normal given the youth of these new modalities, the need to find effective web-based or blended treatments is increasingly urgent. Furthermore, when it comes to clinical applications, the choice of what should be interactive is not trivial. Indeed, it has been shown that therapists believe that the complexity of patients' problems requires tailored blended treatment. It has also been found that therapists and patients have different points of view regarding what components of the therapy they would prefer to be presented in a web-based-remote way [59]. The parts of treatment that can best be offered on the web or face to face can differ among patients (based on ability, preference, severity, and type of problems) and should thus be considered for each patient individually [59]. For that reason, further studies should explore patients' preferences, not only about the content of the intervention but also the type of intervention (face-to-face, web-based, or blended) they prefer. Another point that is currently lacking in the retrieved literature concerns the stigma of mental health care [78] and how different modalities of delivery of treatments might address this issue. Indeed, mental health stigma has been found to have a small- to moderate-sized negative effect on help-seeking behaviors [79]. Interestingly, web-based interventions might be specifically built to target mental health stigma [80].

Patients and survivors might benefit from blended interventions as they have the potential benefits of face-to-face and web-based approaches. In particular, through a blended intervention, patients might maintain the therapeutic alliance with the therapist without the necessity of meeting them weekly because of, for example, a website in which they have to do some homework to practice the skills learned during the face-to-face session. We believe that an integrative intervention based on both traditional CBT and contemporary CBT would be the best choice.

\section{Future Directions: "Change of Recurrence"}

\section{Overview}

On the basis of the retrieved evidence, we propose the hypothetical program of an intervention for FCR based on both traditional CBT and contemporary CBT, named Change Of Recurrence, which aimed to improve the management of FCR in patients with cancer and survivors. We would opt for a blended intervention for 3 reasons. First, given the health emergency that we have been experiencing for the COVID-19 outbreak, a blended intervention would allow us to guarantee the safety of the patient who will rarely have to go to the hospital while maintaining the therapeutic alliance, which is fundamental to the effectiveness of any psychological intervention [81]. Web-based interventions are generally well-received by patients with cancer and might enhance comprehensive care [82], whereas blended therapy overcomes the disadvantages of the lack of alliance between eHealth interventions, maintaining the benefits of a face-to-face intervention [59-61] and the cost reduction and increased accessibility of delivering mental health care [83]. Furthermore, in the retrieved literature, the blended modality resulted as effective in reducing the FCR with moderate-to-large effect sizes, maintained across time $[41,47,63,71]$. Overall, we propose an intervention based on a mix of the key elements that characterize the effective approaches retrieved in the aforementioned literature (CBT, $\mathrm{ACT}$, and mindfulness), delivered through a combination of face-to-face and remote sessions and psychoeducational material.

The program would be structured by first conducting face-to-face sessions at the hospital where the patient is treated or where the survivor undergoes check-ups. This choice could help patients and survivors follow the therapy, especially if we insert the session on the same day that the patient or survivor goes to the hospital for other visits or checks. Indeed, dropout from psychological interventions is a relevant issue to be considered. In addition, we will create a web-based platform comprising 10 modules that can be accessed only when patients finish the previous one. The web-based platform will provide interactive sessions, psychoeducational exercises, and homework. The latter has the objective of trying to render patients as autonomous as possible by applying the techniques learned in the face-to-face sessions.

\section{First Face-to-face Session}

During the first face-to-face session, the therapist gets to know the patient, assessing the level of FCR both qualitatively and quantitatively, using the questionnaire Fear of Cancer Recurrence Inventory. In particular, the patient provides details about him or herself and has the opportunity to discuss diagnosis; treatment; recovery; and, in general, his or her experience. Moreover, this will be a psychoeducational session in which the therapist will explain the FCR model, identify the internal and external triggers that increase the FCR, and focus 
on the patient's FCR experience, particularly on their maladaptive thoughts and coping strategies. At the end of the session, the therapist will give the patients a link to the web-based platform. Through the platform, the patients will be asked to write their negative automatic thoughts using a typical 3-column grid.

\section{First Web-Based Session}

In the first web-based module, the patient will find a summary of the key concepts addressed during the first face-to-face session and exercises to do, such as writing down the thoughts and actions that he or she performs and that increase the FCR.

\section{Second Face-to-face Session}

During the second face-to-face session, the therapist will discuss the patient's homework to clarify the eventual unsolved aspects. In this way, the patient will be encouraged to share his or her experience and start to work on it. The therapist will then introduce the notion of cognitive restructuring, and through the Socratic questioning of cognitive therapy, attempt to challenge the negative automatic thoughts written by the patient during homework. Finally, the therapist and patient will start to reframe negative thinking into alternative thoughts that are more based on reality to explain the homework that the patient will have to do during the week.

\section{Second Web-Based Session}

In the second web-based module, the patient will find a summary of the key concepts addressed during the second face-to-face session. The assigned homework that the patient will have to do is to write the negative automatic thoughts using a typical 5-column grid and reframe them into realistic thinking.

\section{Third Web-Based Interactive Session}

During the third web-based interactive session, the therapist will review the patient's homework. Then, the therapist and the patient will discuss their thoughts and feelings related to cancer and the actions they will take to get rid of or escape those feelings and those that increase the FCR. In particular, the therapist will provide psychoeducational concepts about worry, explaining the importance of expressing fears. To do that, the patient will have to describe their worst-fear scenario related to cancer, providing thoughts and behaviors that he or she will engage in. Then, the therapist will use metaphors such as the bus metaphor, in which the patient will identify thoughts, feelings, and memories or images as passengers persistently challenging cancer. In this way, the patients will learn to actively accept, defuse, and respond compassionately to passengers while not allowing them to dominate their lives. Finally, the therapist will introduce the concept of relaxation, in particular, body scan meditation.

\section{Fourth Web-Based Session}

Following the third module, the patient will find a summary of the key concepts addressed during the third face-to-face session on his or her platform. The patient will also be provided with other metaphors and experiential exercises (eg, daily body scan meditation) aimed at improving the strategies built in the web-based interactive session with the therapist.

\section{Fourth Face-to-face Session}

During the fourth face-to-face session, the therapist will focus on adaptive coping strategies that enhance acceptance, cognitive defusion, awareness, and psychological flexibility in general. In this way, the patient will begin to become aware and accept thoughts and emotions about cancer, eliminate rigid thoughts and beliefs about cancer, and define personal values and commit to pursuing meaningful activities in line with those values. Finally, the therapist will introduce the concept of mindfulness and its basic principles.

\section{Fifth Web-Based Session}

In this web-based module, the patient will be provided with a summary of the key concepts addressed during the fourth face-to-face session, with particular attention to mindfulness. Specifically, the patient will be presented with mindfulness and relaxation exercises through audio and videotape. The audio clips will contain fully automated exercises meant to bring awareness to breathing and bodily sensations. The video clips will provide additional explanations on the techniques, along with some practical guidelines on how to practice during the daytime without clips.

\section{Fifth Face-to-face Session}

During the last face-to-face session, the therapist will evaluate the changes that occurred in the patient's emotional and cognitive reactions, making a summary of the current situation and the changes that occurred. The therapist and the patient will talk about the differences between how the patient coped with FCR before the treatment and how he or she copes now. Moreover, the therapist and the patient will draw up an action plan based on the patient's values. Finally, the therapist will build, together with the patient, an exercise schedule to maintain the improvements. The contents of the exercises (audio or video clips) will be available on patients' platforms and will be accessible for a year.

\section{Follow-up Web-Based Interactive Session}

A final web-based interactive session will be provided 1 month after the fifth face-to-face session to monitor the psychological state of the patients.

If effective, this program would lead to a time and cost-saving care pathway for treating FCR, putting together the benefits of real-time interaction with the clinical staff and the ease of having tailored clinical materials available daily to allow for a continuous improvement.

\section{Conclusions}

To conclude, this overview has some limitations. Regarding the first part (review of the psychological interventions), the limitations of the methodology of the included studies and between-study heterogeneity reduced the overall strength of the evidence. Moreover, some of the studies were selected from other systematic reviews, whereas others were selected manually. Regarding the second part, it is only a preprotocol that must be evaluated by experts and patients. 


\section{Conflicts of Interest}

None declared.

\section{References}

1. Pizzoli SF, Renzi C, Arnaboldi P, Russell-Edu W, Pravettoni G. From life-threatening to chronic disease: is this the case of cancers? A systematic review. Cogent Psychol 2019 Feb 26;6(1) [FREE Full text] [doi: 10.1080/23311908.2019.1577593]

2. Lebel S, Ozakinci G, Humphris G, Thewes B, Prins J, Dinkel A, et al. Current state and future prospects of research on fear of cancer recurrence. Psychooncology 2017 Apr;26(4):424-427 [FREE Full text] [doi: 10.1002/pon.4103] [Medline: 26891602]

3. Simonelli L, Siegel SD, Duffy NM. Fear of cancer recurrence: a theoretical review and its relevance for clinical presentation and management. Psychooncology 2017 Oct;26(10):1444-1454 [FREE Full text] [doi: 10.1002/pon.4168] [Medline: 27246348]

4. Chen D. Fear of cancer recurrence: a systematic review of randomized, controlled trials. Oncol Nurs Forum 2018 Oct 19:703-712 [FREE Full text] [doi: 10.1188/18.onf.703-712]

5. Tauber N, O'Toole MS, Dinkel A, Galica J, Humphris G, Lebel S, et al. Effect of psychological intervention on fear of cancer recurrence: a systematic review and meta-analysis. J Clin Oncol 2019 Nov 01;37(31):2899-2915 [FREE Full text] [doi: 10.1200/JCO.19.00572] [Medline: 31532725]

6. Ray P, Haideri N, Haque I, Mohammed O, Chakraborty S, Banerjee S, et al. The impact of nanoparticles on the immune system: a gray zone of nanomedicine. J Immunol Sci 2021 Feb 01;5(1):19-33. [doi: 10.29245/2578-3009/2021/1.1206]

7. Brivio E, Oliveri S, Pravettoni G. Empowering communication in emergency contexts: reflections from the Italian coronavirus outbreak. Mayo Clin Proc 2020 May;95(5):849-851 [FREE Full text] [doi: 10.1016/j.mayocp.2020.03.021] [Medline: 32370848]

8. Chen G, Wu Q, Jiang H, Zhang H, Peng J, Hu J, et al. Fear of disease progression and psychological stress in cancer patients under the outbreak of COVID-19. Psychooncology 2020 Sep;29(9):1395-1398 [FREE Full text] [doi: 10.1002/pon.5451] [Medline: 32596867]

9. Sebri V, Cincidda C, Savioni L, Ongaro G, Pravettoni G. Worry during the initial height of the COVID-19 crisis in an Italian sample. J Gen Psychol 2021 Jul;148(3):327-359 [FREE Full text] [doi: 10.1080/00221309.2021.1878485] [Medline: $\underline{33522456]}$

10. Cincidda C, Pizzoli SF, Oliveri S, Pravettoni G. Regulation strategies during Covid-19 quarantine: the mediating effect of worry on the links between coping strategies and anxiety. Eur Rev Appl Psychol 2021 Jun:100671. [doi:

10.1016/j.erap.2021.100671]

11. Hall D, Luberto CM, Philpotts LL, Song R, Park ER, Yeh GY. Mind-body interventions for fear of cancer recurrence: a systematic review and meta-analysis. Psychooncology 2018 Nov;27(11):2546-2558 [FREE Full text] [doi: 10.1002/pon.4757] [Medline: 29744965]

12. Sharpe L, Thewes B, Butow P. Current directions in research and treatment of fear of cancer recurrence. Curr Opin Support Palliat Care 2017 Sep;11(3):191-196 [FREE Full text] [doi: 10.1097/SPC.0000000000000288] [Medline: 28665813]

13. Islind AS, Johansson V, Vallo Hult H, Alsén P, Andreasson E, Angenete E, et al. Individualized blended care for patients with colorectal cancer: the patient's view on informational support. Support Care Cancer 2021 Jun 12;29(6):3061-3067 [FREE Full text] [doi: 10.1007/s00520-020-05810-5] [Medline: $\underline{33044626]}$

14. Al-Quteimat O, Amer AM. The impact of the COVID-19 pandemic on cancer patients. Am J Clin Oncol 2020 Jun;43(6):452-455 [FREE Full text] [doi: 10.1097/COC.0000000000000712] [Medline: $\underline{\text { 32304435] }}$

15. Curigliano G, Banerjee S, Cervantes A, Garassino M, Garrido P, Girard N, Panel Members. Managing cancer patients during the COVID-19 pandemic: an ESMO multidisciplinary expert consensus. Ann Oncol 2020 Oct;31(10):1320-1335 [FREE Full text] [doi: 10.1016/j.annonc.2020.07.010] [Medline: 32745693]

16. Wang Y, Duan Z, Ma Z, Mao Y, Li X, Wilson A, et al. Epidemiology of mental health problems among patients with cancer during COVID-19 pandemic. Transl Psychiatry 2020 Jul 31;10(1):263 [FREE Full text] [doi: 10.1038/s41398-020-00950-y] [Medline: 32737292]

17. Herschbach P, Book K, Dinkel A, Berg P, Waadt S, Duran G, et al. Evaluation of two group therapies to reduce fear of progression in cancer patients. Support Care Cancer 2010 Apr;18(4):471-479 [FREE Full text] [doi: 10.1007/s00520-009-0696-1] [Medline: 19865833]

18. Humphris G, Rogers S. AFTER and beyond: cancer recurrence fears and a test of an intervention in oral and oropharyngeal patients. Soc Sci Dentistry 2012;2(1):29-38 [FREE Full text]

19. Lebel S, Maheu C, Lefebvre M, Secord S, Courbasson C, Singh M, et al. Addressing fear of cancer recurrence among women with cancer: a feasibility and preliminary outcome study. J Cancer Surviv 2014 Sep;8(3):485-496 [FREE Full text] [doi: 10.1007/s11764-014-0357-3] [Medline: 24756313]

20. Manne S, Virtue SM, Ozga M, Kashy D, Heckman C, Kissane D, et al. A comparison of two psychological interventions for newly-diagnosed gynecological cancer patients. Gynecol Oncol 2017 Feb;144(2):354-362 [FREE Full text] [doi: 10.1016/j.ygyno.2016.11.025] [Medline: 27887806] 
21. Merckaert I, Lewis F, Delevallez F, Herman S, Caillier M, Delvaux N, et al. Improving anxiety regulation in patients with breast cancer at the beginning of the survivorship period: a randomized clinical trial comparing the benefits of single-component and multiple-component group interventions. Psychooncology 2017 Aug;26(8):1147-1154 [FREE Full text] [doi: 10.1002/pon.4294] [Medline: 27718533]

22. Savard J, Savard M, Caplette-Gingras A, Casault L, Camateros C. Development and feasibility of a group cognitive-behavioral therapy for fear of cancer recurrence. Cognit Behav Pract 2018 May;25(2):275-285 [FREE Full text] [doi: 10.1016/j.cbpra.2017.08.001]

23. Tomei C, Lebel S, Maheu C, Lefebvre M, Harris C. Examining the preliminary efficacy of an intervention for fear of cancer recurrence in female cancer survivors: a randomized controlled clinical trial pilot study. Support Care Cancer 2018 Aug;26(8):2751-2762 [FREE Full text] [doi: 10.1007/s00520-018-4097-1] [Medline: 29500582]

24. Heinrichs N, Zimmermann T, Huber B, Herschbach P, Russel DW, Baucom DH. Cancer distress reduction with a couple-based skills training: a randomized controlled trial. Ann Behav Med 2012 Apr;43(2):239-252 [FREE Full text] [doi: 10.1007/s12160-011-9314-9] [Medline: 22037965]

25. Momino K, Mitsunori M, Yamashita H, Toyama T, Sugiura H, Yoshimoto N, et al. Collaborative care intervention for the perceived care needs of women with breast cancer undergoing adjuvant therapy after surgery: a feasibility study. Jpn J Clin Oncol 2017 Mar 01;47(3):213-220 [FREE Full text] [doi: 10.1093/jjco/hyw189] [Medline: 28003321]

26. Kabat-Zinn J. Mindfulness-based interventions in context: past, present, and future. Clin Psychol Sci Pract 2003;10(2):144-156 [FREE Full text] [doi: 10.1093/clipsy.bpg016]

27. Compen F, Bisseling E, Schellekens M, Donders R, Carlson L, van der Lee M, et al. Face-to-face and internet-based mindfulness-based cognitive therapy compared with treatment as usual in reducing psychological distress in patients with cancer: a multicenter randomized controlled trial. J Clin Oncol 2018 Aug 10;36(23):2413-2421 [FREE Full text] [doi: $10.1200 / j \operatorname{co} .2017 .76 .5669]$

28. Lengacher C, Johnson-Mallard V, Post-White J, Moscoso MS, Jacobsen PB, Klein TW, et al. Randomized controlled trial of mindfulness-based stress reduction (MBSR) for survivors of breast cancer. Psychooncology 2009 Dec;18(12):1261-1272 [FREE Full text] [doi: 10.1002/pon.1529] [Medline: 19235193]

29. Lengacher C, Johnson-Mallard V, Barta M, Fitzgerald S, Moscoso MS, Post-White J, et al. Feasibility of a mindfulness-based stress reduction program for early-stage breast cancer survivors. J Holist Nurs 2011 Jun;29(2):107-117 [FREE Full text] [doi: 10.1177/0898010110385938] [Medline: 21041554]

30. Lengacher C, Shelton MM, Reich RR, Barta MK, Johnson-Mallard V, Moscoso MS, et al. Mindfulness based stress reduction (MBSR(BC)) in breast cancer: evaluating fear of recurrence (FOR) as a mediator of psychological and physical symptoms in a randomized control trial (RCT). J Behav Med 2014 Apr;37(2):185-195 [FREE Full text] [doi: 10.1007/s10865-012-9473-6] [Medline: 23184061]

31. Lengacher C, Reich RR, Paterson CL, Ramesar S, Park JY, Alinat C, et al. Examination of broad symptom improvement resulting from mindfulness-based stress reduction in breast cancer survivors: a randomized controlled trial. J Clin Oncol 2016 Aug 20;34(24):2827-2834 [FREE Full text] [doi: 10.1200/jco.2015.65.7874]

32. Victorson D, Hankin V, Burns J, Weiland R, Maletich C, Sufrin N, et al. Feasibility, acceptability and preliminary psychological benefits of mindfulness meditation training in a sample of men diagnosed with prostate cancer on active surveillance: results from a randomized controlled pilot trial. Psychooncology 2017 Aug;26(8):1155-1163 [FREE Full text] [doi: 10.1002/pon.4135] [Medline: 27145355]

33. Crane-Okada R, Kiger H, Sugerman F, Uman GC, Shapiro SL, Wyman-McGinty W, et al. Mindful movement program for older breast cancer survivors: a pilot study. Cancer Nurs 2012;35(4):1-13 [FREE Full text] [doi: 10.1097/NCC.0b013e3182280f73] [Medline: 22705939]

34. Hayes S, Luoma JB, Bond FW, Masuda A, Lillis J. Acceptance and commitment therapy: model, processes and outcomes. Behav Res Ther 2006 Jan;44(1):1-25 [FREE Full text] [doi: 10.1016/j.brat.2005.06.006] [Medline: 16300724]

35. Arch J, Mitchell JL. An Acceptance and Commitment Therapy (ACT) group intervention for cancer survivors experiencing anxiety at re-entry. Psychooncology 2016 May;25(5):610-615 [FREE Full text] [doi: 10.1002/pon.3890] [Medline: 26130586]

36. Johns SA, Stutz PV, Talib TL, Cohee AA, Beck-Coon KA, Brown LF, et al. Acceptance and commitment therapy for breast cancer survivors with fear of cancer recurrence: a 3-arm pilot randomized controlled trial. Cancer 2020 Jan 01;126(1):211-218 [FREE Full text] [doi: 10.1002/cncr.32518] [Medline: $\underline{\text { 31539169] }}$

37. Marín F, Luciano C. Acceptance of relapse fears in breast cancer patients: effects of an ACT-based abridged intervention. Psicooncología 2016;13(1):7-21 [FREE Full text]

38. Butow P, Bell ML, Smith AB, Fardell JE, Thewes B, Turner J, Members of the Conquer Fear Authorship Group. Conquer fear: protocol of a randomised controlled trial of a psychological intervention to reduce fear of cancer recurrence. BMC Cancer 2013 Apr 23;13:201 [FREE Full text] [doi: 10.1186/1471-2407-13-201] [Medline: 23617696]

39. Butow P, Turner J, Gilchrist J, Sharpe L, Smith AB, Fardell JE, et al. Randomized trial of conquerfear: a novel, theoretically based psychosocial intervention for fear of cancer recurrence. J Clin Oncol 2017 Dec 20;35(36):4066-4077 [FREE Full text] [doi: $\underline{10.1200 / j c 0.2017 .73 .1257]}$ 
40. Smith A, Thewes B, Turner J, Gilchrist J, Fardell J, Sharpe L, et al. Pilot of a theoretically grounded psychologist-delivered intervention for fear of cancer recurrence (Conquer Fear). Psychooncology 2015 Aug;24(8):967-970 [FREE Full text] [doi: 10.1002/pon.3775] [Medline: 25728489]

41. van de Wal M, Servaes P, Berry R, Thewes B, Prins J. Cognitive behavior therapy for fear of cancer recurrence: a case study. J Clin Psychol Med Settings 2018 Dec;25(4):390-407 [FREE Full text] [doi: 10.1007/s10880-018-9545-z] [Medline: 29468568]

42. Richards D, Richardson T. Computer-based psychological treatments for depression: a systematic review and meta-analysis. Clin Psychol Rev 2012 Jun;32(4):329-342 [FREE Full text] [doi: 10.1016/j.cpr.2012.02.004] [Medline: 22466510]

43. Meier C, Fitzgerald MC, Smith JM. eHealth: extending, enhancing, and evolving health care. Annu Rev Biomed Eng 2013;15:359-382 [FREE Full text] [doi: 10.1146/annurev-bioeng-071812-152350] [Medline: 23683088]

44. van Helmondt SJ, van der Lee ML, van Woezik RA, Lodder P, de Vries J. No effect of CBT-based online self-help training to reduce fear of cancer recurrence: first results of the CAREST multicenter randomized controlled trial. Psychooncology 2020 Jan 13;29(1):86-97 [FREE Full text] [doi: 10.1002/pon.5233] [Medline: 31595627]

45. Elbert N, van Os-Medendorp H, van Renselaar W, Ekeland AG, van Roijen LH, Raat H, et al. Effectiveness and cost-effectiveness of eHealth interventions in somatic diseases: a systematic review of systematic reviews and meta-analyses. J Med Internet Res 2014 Apr 16;16(4):e110 [FREE Full text] [doi: 10.2196/jmir.2790] [Medline: 24739471]

46. Triberti S, Savioni L, Sebri V, Pravettoni G. eHealth for improving quality of life in breast cancer patients: a systematic review. Cancer Treat Rev 2019 Mar;74:1-14 [FREE Full text] [doi: 10.1016/j.ctrv.2019.01.003] [Medline: 30658289]

47. Burm R, Thewes B, Rodwell L, Kievit W, Speckens A, van de Wal M, et al. Long-term efficacy and cost-effectiveness of blended cognitive behavior therapy for high fear of recurrence in breast, prostate and colorectal Cancer survivors: follow-up of the SWORD randomized controlled trial. BMC Cancer 2019 May 16;19(1):462 [FREE Full text] [doi:

10.1186/s12885-019-5615-3] [Medline: 31096934]

48. Wentzel J, van der Vaart R, Bohlmeijer ET, van Gemert-Pijnen JE. Mixing online and face-to-face therapy: how to benefit from blended care in mental health care. JMIR Ment Health 2016 Feb 09;3(1):e9 [FREE Full text] [doi: 10.2196/mental.4534] [Medline: 26860537]

49. Heiniger L, Smith AB, Olver I, Grimison P, Klein B, Wootten A, et al. e-TC: development and pilot testing of a web-based intervention to reduce anxiety and depression in survivors of testicular cancer. Eur J Cancer Care (Engl) 2017 Nov;26(6) [FREE Full text] [doi: 10.1111/ecc.12698] [Medline: 28544085]

50. Slev V, Mistiaen P, Pasman HR, Verdonck-de Leeuw IM, van Uden-Kraan CF, Francke AL. Effects of eHealth for patients and informal caregivers confronted with cancer: a meta-review. Int J Med Inform 2016 Mar;87:54-67 [FREE Full text] [doi: 10.1016/j.ijmedinf.2015.12.013] [Medline: 26806712]

51. Lichtenthal W, Corner GW, Slivjak ET, Roberts KE, Li Y, Breitbart W, et al. A pilot randomized controlled trial of cognitive bias modification to reduce fear of breast cancer recurrence. Cancer 2017 Apr 15;123(8):1424-1433 [FREE Full text] [doi: 10.1002/cncr.30478] [Medline: 28055119]

52. van Helmondt SJ, van der Lee ML, de Vries J. Study protocol of the CAREST-trial: a randomised controlled trial on the (cost-) effectiveness of a CBT-based online self-help training for fear of cancer recurrence in women with curatively treated breast cancer. BMC Cancer 2016 Jul 25;16:527 [FREE Full text] [doi: 10.1186/s12885-016-2562-0] [Medline: 27455846]

53. Lengacher C, Reich RR, Ramesar S, Alinat CB, Moscoso M, Cousin L, et al. Feasibility of the mobile mindfulness-based stress reduction for breast cancer (mMBSR(BC)) program for symptom improvement among breast cancer survivors. Psychooncology 2018 Feb;27(2):524-531 [FREE Full text] [doi: 10.1002/pon.4491] [Medline: 28665541]

54. Hadlandsmyth K, Dindo LN, Wajid R, Sugg SL, Zimmerman MB, Rakel BA. A single-session acceptance and commitment therapy intervention among women undergoing surgery for breast cancer: a randomized pilot trial to reduce persistent postsurgical pain. Psychooncology 2019 Nov;28(11):2210-2217 [FREE Full text] [doi: 10.1002/pon.5209] [Medline: 31430830]

55. Köhle N, Drossaert CH, Schreurs KM, Hagedoorn M, Verdonck-de Leeuw IM, Bohlmeijer ET. A web-based self-help intervention for partners of cancer patients based on Acceptance and Commitment Therapy: a protocol of a randomized controlled trial. BMC Public Health 2015 Mar 28;15:303 [FREE Full text] [doi: 10.1186/s12889-015-1656-y] [Medline: 25884187]

56. Köhle N, Drossaert CH, Jaran J, Schreurs KM, Verdonck-de Leeuw IM, Bohlmeijer ET. User-experiences with a web-based self-help intervention for partners of cancer patients based on acceptance and commitment therapy and self-compassion: a qualitative study. BMC Public Health 2017 Feb 28;17(1):225 [FREE Full text] [doi: 10.1186/s12889-017-4121-2] [Medline: 28245794]

57. Mendes-Santos C, Weiderpass E, Santana R, Andersson G. A guided internet-delivered individually-tailored ACT-influenced cognitive behavioural intervention to improve psychosocial outcomes in breast cancer survivors (iNNOVBC): study protocol. Internet Interv 2019 Sep;17:100236 [FREE Full text] [doi: 10.1016/j.invent.2019.01.004] [Medline: 30949435]

58. Smith A, Bamgboje-Ayodele A, Butow P, Klein B, Turner J, Sharpe L, iConquerFear Community Advisory Group, et al. Development and usability evaluation of an online self-management intervention for fear of cancer recurrence (iConquerFear). Psychooncology 2020 Jan;29(1):98-106 [FREE Full text] [doi: 10.1002/pon.5218] [Medline: 31483911] 
59. van der Vaart R, Witting M, Riper H, Kooistra L, Bohlmeijer ET, van Gemert-Pijnen LJ. Blending online therapy into regular face-to-face therapy for depression: content, ratio and preconditions according to patients and therapists using a Delphi study. BMC Psychiatry 2014 Dec 14;14:355 [FREE Full text] [doi: 10.1186/s12888-014-0355-z] [Medline: 25496393]

60. Schuster R, Pokorny R, Berger T, Topooco N, Laireiter AR. The advantages and disadvantages of online and blended therapy: survey study amongst licensed psychotherapists in Austria. J Med Internet Res 2018 Dec 18;20(12):e11007 [FREE Full text] [doi: 10.2196/11007] [Medline: 30563817]

61. Andersson G, Titov N. Advantages and limitations of internet-based interventions for common mental disorders. World Psychiatry 2014 Feb;13(1):4-11 [FREE Full text] [doi: 10.1002/wps.20083] [Medline: 24497236]

62. Kelders S, Bohlmeijer ET, Pots WT, van Gemert-Pijnen JE. Comparing human and automated support for depression: fractional factorial randomized controlled trial. Behav Res Ther 2015 Sep;72:72-80 [FREE Full text] [doi: 10.1016/j.brat.2015.06.014] [Medline: 26196078]

63. van de Wal M, Thewes B, Gielissen M, Speckens A, Prins J. Efficacy of blended cognitive behavior therapy for high fear of recurrence in breast, prostate, and colorectal cancer survivors: the SWORD study, a randomized controlled trial. J Clin Oncol 2017 Jul 01;35(19):2173-2183 [FREE Full text] [doi: 10.1200/jco.2016.70.5301]

64. Lungu A, Jun JJ, Azarmanesh O, Leykin Y, Chen CE. Blended care-cognitive behavioral therapy for depression and anxiety in real-world settings: pragmatic retrospective study. J Med Internet Res 2020 Jul 06;22(7):e18723 [FREE Full text] [doi: 10.2196/18723] [Medline: $\underline{32628120}$ ]

65. Anderson S, Tambling R, Yorgason JB, Rackham E. The mediating role of the therapeutic alliance in understanding early discontinuance. Psychother Res 2019 Oct;29(7):882-893 [FREE Full text] [doi: 10.1080/10503307.2018.1506949] [Medline: $\underline{\text { 30079816] }}$

66. Rumpold G, Doering S, Smrekar U, Schubert C, Koza R, Schatz DS, et al. Changes in motivation and the therapeutic alliance during a pretherapy diagnostic and motivation-enhancing phase among psychotherapy outpatients. Psychother Res 2005 Jan;15(1-2):117-127 [FREE Full text] [doi: 10.1080/10503300512331327092]

67. Erbe D, Eichert HC, Riper H, Ebert DD. Blending face-to-face and internet-based interventions for the treatment of mental disorders in adults: systematic review. J Med Internet Res 2017 Sep 15;19(9):e306 [FREE Full text] [doi: 10.2196/jmir.6588] [Medline: 28916506]

68. Etzelmueller A, Radkovsky A, Hannig W, Berking M, Ebert DD. Patient's experience with blended video- and internet based cognitive behavioural therapy service in routine care. Internet Interv 2018 Jun;12:165-175 [FREE Full text] [doi: 10.1016/j.invent.2018.01.003] [Medline: 30135780]

69. Andrews G, Basu A, Cuijpers P, Craske M, McEvoy P, English C, et al. Computer therapy for the anxiety and depression disorders is effective, acceptable and practical health care: an updated meta-analysis. J Anxiety Disord 2018 Apr;55:70-78 [FREE Full text] [doi: 10.1016/j.janxdis.2018.01.001] [Medline: 29422409]

70. Baumeister H, Reichler L, Munzinger M, Lin J. The impact of guidance on Internet-based mental health interventions A systematic review. Int Interv 2014 Oct;1(4):205-215 [FREE Full text] [doi: 10.1016/j.invent.2014.08.003]

71. van de Wal MA, Gielissen MF, Servaes P, Knoop H, Speckens AE, Prins JB. Study protocol of the SWORD-study: a randomised controlled trial comparing combined online and face-to-face cognitive behaviour therapy versus treatment as usual in managing fear of cancer recurrence. BMC Psychol 2015;3(1):12 [FREE Full text] [doi: 10.1186/s40359-015-0068-1] [Medline: 25977758]

72. Luigjes-Huizer Y, van der Lee ML, de Wit NJ, Helsper CW. Study protocol of the BLANKET trial: a cluster randomised controlled trial on the (cost-) effectiveness of a primary care intervention for fear of cancer recurrence in cancer survivors. BMJ Open 2019 Dec 02;9(12):e032616 [FREE Full text] [doi: 10.1136/bmjopen-2019-032616] [Medline: $\underline{31796488]}$

73. Leermakers L, Döking S, Thewes B, Braamse AM, Gielissen MF, de Wilt JH, et al. Study protocol of the CORRECT multicenter trial: the efficacy of blended cognitive behavioral therapy for reducing psychological distress in colorectal cancer survivors. BMC Cancer 2018 Jul 18;18(1):748 [FREE Full text] [doi: 10.1186/s12885-018-4645-6] [Medline: $\underline{30021555]}$

74. Döking S, Koulil SS, Thewes B, Braamse AM, Custers JA, Prins JB. Combined face-to-face and online cognitive-behavioral therapy for high distress of colorectal cancer survivors: a case study. Cognit Behav Pract 2021 Feb;28(1):107-123 [FREE Full text] [doi: 10.1016/j.cbpra.2020.06.008]

75. Lyhne JD, Smith A, Frostholm L, Fink P, Jensen LH. Study protocol: a randomized controlled trial comparing the efficacy of therapist guided internet-delivered cognitive therapy (TG-iConquerFear) with augmented treatment as usual in reducing fear of cancer recurrence in Danish colorectal cancer survivors. BMC Cancer 2020 Mar 16;20(1):223 [FREE Full text] [doi: 10.1186/s12885-020-06731-6] [Medline: 32178640]

76. Cillessen L, Schellekens MP, Van de Ven M, Donders A, Compen FR, Bisseling EM, et al. Consolidation and prediction of long-term treatment effect of group and online mindfulness-based cognitive therapy for distressed cancer patients. Acta Oncologica 2018 Jun 22;57(10):1293-1302 [FREE Full text] [doi: 10.1080/0284186x.2018.1479071]

77. Matis J, Svetlak M, Slezackova A, Svoboda M, Šumec R. Mindfulness-based programs for patients with cancer via ehealth and mobile health: systematic review and synthesis of quantitative research. J Med Internet Res 2020 Nov 16;22(11):e20709 [FREE Full text] [doi: 10.2196/20709] [Medline: 33196452] 
78. Corrigan P, Mittal D, Reaves CM, Haynes TF, Han X, Morris S, et al. Mental health stigma and primary health care decisions. Psychiatry Res 2014 Aug 15;218(1-2):35-38 [FREE Full text] [doi: 10.1016/j.psychres.2014.04.028] [Medline: 24774076]

79. Clement S, Schauman O, Graham T, Maggioni F, Evans-Lacko S, Bezborodovs N, et al. What is the impact of mental health-related stigma on help-seeking? A systematic review of quantitative and qualitative studies. Psychol Med 2014 Feb 21;45(1):11-27 [FREE Full text] [doi: 10.1017/s0033291714000129]

80. Nickerson A, Byrow Y, Pajak R, McMahon T, Bryant RA, Christensen H, et al. 'Tell Your Story': a randomized controlled trial of an online intervention to reduce mental health stigma and increase help-seeking in refugee men with posttraumatic stress. Psychol Med 2019 Apr 11;50(5):781-792 [FREE Full text] [doi: 10.1017/s0033291719000606]

81. Ardito R, Rabellino D. Therapeutic alliance and outcome of psychotherapy: historical excursus, measurements, and prospects for research. Front Psychol 2011;2:270 [FREE Full text] [doi: 10.3389/fpsyg.2011.00270] [Medline: 22028698]

82. Willems R, Bolman CA, Lechner L, Mesters I, Gunn KM, Ross XS, et al. Online interventions aimed at reducing psychological distress in cancer patients: evidence update and suggestions for future directions. Curr Opin Support Palliat Care 2020 Mar;14(1):27-39 [FREE Full text] [doi: 10.1097/SPC.0000000000000483] [Medline: 31895066]

83. Davies F, Shepherd HL, Beatty L, Clark B, Butow P, Shaw J. Implementing web-based therapy in routine mental health care: systematic review of health professionals' perspectives. J Med Internet Res 2020 Jul 23;22(7):e17362 [FREE Full text] [doi: 10.2196/17362] [Medline: $\underline{\text { 32706713] }}$

\author{
Abbreviations \\ ACT: acceptance and commitment therapy \\ AIM-FBCR: Attention and Interpretation Modification for Fear of Breast Cancer Recurrence \\ BC: breast cancer \\ BC-CBT: blended care cognitive behavioral therapy treatment \\ CBT: cognitive behavioral therapy \\ eMBCT: internet-delivered mindfulness-based cognitive therapy \\ FCR: fear of cancer recurrence \\ MBCT: mindfulness-based cognitive therapy \\ MBSR: mindfulness-based stress reduction \\ QoL: quality of life \\ RCT: randomized controlled trial
}

Edited by G Eysenbach; submitted 19.04.21; peer-reviewed by B Green, P Ray; comments to author 11.06.21; revised version received 08.10.21; accepted 28.10.21; published 11.01.22

Please cite as:

Cincidda C, Pizzoli SFM, Pravettoni G

Remote Psychological Interventions for Fear of Cancer Recurrence: Scoping Review

JMIR Cancer 2022;8(1):e29745

URL: https://cancer.jmir.org/2022/1/e29745

doi: $10.2196 / 29745$

PMID:

(C) Clizia Cincidda, Silvia Francesca Maria Pizzoli, Gabriella Pravettoni. Originally published in JMIR Cancer (https://cancer.jmir.org), 11.01.2022. This is an open-access article distributed under the terms of the Creative Commons Attribution License (https://creativecommons.org/licenses/by/4.0/), which permits unrestricted use, distribution, and reproduction in any medium, provided the original work, first published in JMIR Cancer, is properly cited. The complete bibliographic information, a link to the original publication on https://cancer.jmir.org/, as well as this copyright and license information must be included. 